FINANCING AND PAYMENT ISSUES IN RURAL LONG TERM CARE INTEGRATION

MUSKIE

SCHOOL 


\title{
FINANCING AND PAYMENT ISSUES IN RURAL LONG TERM CARE INTEGRATION
}

\author{
Paul Saucier \\ Julie Fralich
}

Working Paper \#21

Maine Rural Health Research Center

Edmund S. Muskie School of Public Service

University of Southern Maine

96 Falmouth Street PO Box 9300

Portland, Maine 04104-9300

(207) $780-4430$ 


\section{Table of Contents}

Executive Summary.

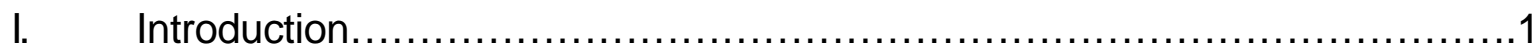

II. Financing and Payment Must Support Specific Program Goals ................2

III. Financing and Payment Must be Compatible With Available Service Delivery Vehicles and Local Market Conditions.................................4

A. Commercial Plans (Including Medicare+Choice Plans) ....................5

B. Medicaid Plans (Including Counties).................................................8

C. Provider Sponsored Organizations...................................................

IV. A Range of Financing and Payment Strategies................................10

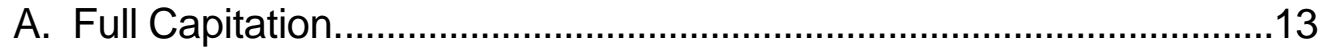

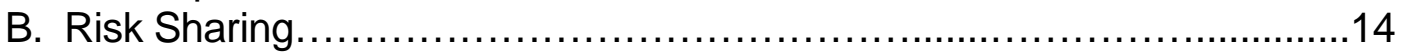

C. Partial Capitation........................................................... 15

D. Administrative Services Arrangements..................................18

E. Managed Fee for Service/Coordination of Care............................18

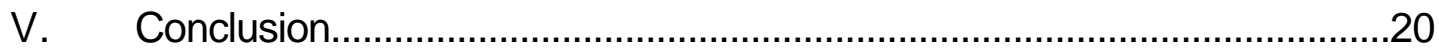

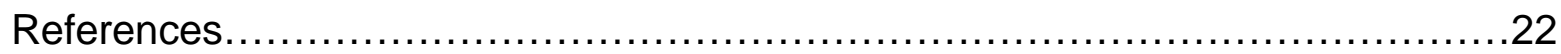




\section{EXECUTIVE SUMMARY}

\section{Purpose}

Federal and state policy makers, consumers, health plans, providers, and other stakeholders are interested in the benefits and disadvantages of integrating acute and long term care financing in rural areas. To date, experience with integrated financing is limited and is based largely in urban areas. This paper reviews current research and experience and identifies key policy and program considerations for integrated financing in rural areas.

\section{Why Integrate Financing?}

A major concern with fee-for-service reimbursement is that it forces consumers and providers into rigid categories of service, whether or not those services truly meet consumers' needs. This is a particular concern when long term care is needed, because public long term care is funded primarily by Medicaid while public acute care is funded primarily by Medicare. The bifurcation of these two important funding sources results in perverse incentives to shift costs and to maximize reimbursement rather than providing the most appropriate level of care to consumers. The hope of integrated financing is that it will provide the financial incentives and flexibility needed to deliver to consumers the appropriate level of care without regard to funding source.

\section{The Urban Model: Financial Integration through Full Capitation}

Integration of acute and long term care financing has been tested primarily in urban areas, and the central design feature has been capitation. Many variations exist, but the general approach has been to create a flexible pool of acute (Medicare) and long term care (Medicaid) dollars at the health plan or provider system level. For each enrolled beneficiary, the State makes a capitated Medicaid payment and the federal Health Care Financing Administration makes a capitated Medicare payment to a single accountable entity. That entity (an HMO, ProviderSponsored Organization or other qualified risk-bearing organization) must provide all covered services and is at financial risk for costs that exceed the capitation, but is freed from many feefor-service rules. The entity has a financial incentive to provide or pay for any service that is likely to prevent more expensive needs down the road, such as hospital or institutional long term care. Capitation allows downward substitution of services when appropriate, makes budgets more predictable for payers and allows a greater focus on consumer outcomes by focusing accountability on a single entity responsible for total care.

\section{Full Capitation Often Not Viable in Rural Areas}

Full capitation is rare is rural areas. Financial integration through full capitation of acute and long term care payments has not been widely replicated in rural areas. Two PACE sites (Program of All-inclusive Care for the Elderly), based in Columbia, South Carolina and Eau Claire, Wisconsin, are fully capitated for both Medicare and Medicaid. Both sites provide services in rural areas but are based in small cities. The Arizona Long Term Care System (ALTCS) provides capitated Medicaid long term care services statewide, but Medicare payments remain fee-for-service, protecting ALTCS contractors from acute care risk. The lack of experience in rural areas is not surprising, because capitation works best where there are large numbers of potential members and providers. A large member base allows managed care organizations to spread risk, and a large provider base gives them leverage in negotiating discounted rates. 
Capitation may be counter to rural health provider goals: In many rural areas, preservation of existing provider infrastructure is an explicit goal. Depending on the type of provider, capitation can have the opposite effect. Capitation provides a financial incentive to the accountable entity (e.g., HMO, PSO) to use less expensive care. Rural hospitals, for example, should expect to receive fewer referrals from a capitated integrated care entity. Likewise, home health agencies might lose business as integrated entities learn how to substitute home care (provided by personal care assistants) for home health (provided by nurses). Furthermore, the integrated entity will want to negotiate discounts from providers, diminishing revenue per unit of service.

Many rural areas lack managed care infrastructure: Full capitation models require managed care infrastructure that often does not exist in rural areas. A financially healthy organization must be available and willing to bear the financial risk that comes with accepting capitated payments. In urban areas, HMOs, Provider-Sponsored Organizations and other managed care entities have played this role, but they have shied away from Medicare and Medicaid programs in rural areas. The alternative, developing a home-grown organization, is very difficut. With insurance laws in most states requiring such organizations to have reserves of $\$ 500,000$ to $\$ 1$ million, financially strapped local providers can not step forward, and those that have the resources may not wish to get into the risk management business because the incentives of capitation are generally opposite the familiar incentives of fee-for-service payment.

High hopes for the BBA have not materialized. Changes in reimbursement for Medicare risk organizations were enacted in the Balanced Budget Act of 1997 to make rural areas more attractive to risk-bearing organizations over time, but no significant increase of Medicare managed care has been observed in rural areas to date. It is too early to tell how modifications enacted in the Medicare, Medicaid and SCHIP Balanced Budget Refinement Act of 1999 will impact rural infrastructure. The Refinement Act provided additional incentives to Medicare+Choice plans to expand into rural areas, but those incentives may be offset by several provisions that delay or mitigate BBA fee-for-service provisions for providers. To the extent that rural providers feel less immediate financial pressure from BBA, they may be less inclined to negotiate with prospective Medicare+Choice plans or to launch provider-based plans of their own.

\section{Rural Alternatives to Full Capitation}

A conclusion of the HCFA-sponsored evaluation of Social HMOs was that integrated financing is necessary but not sufficient to integrate services. Does this suggest that rural areas need not try, given the difficulty of implementing full capitation models? Some policy makers and program designers are experimenting with incremental strategies to determine whether some or all of the benefits of service intergration can be achieved with less than full financial integration. Approaches include managed fee-for-service, partial capitation and other risk limitation mechanisms.

Managed fee-for-service refers to models that continue to pay for services on a fee-forservice basis, but manage the services in various ways. For example, the MaineNET Demonstration Program in rural Maine is designed as a Primary Care Case Management (PCCM) program, in which physician practices serve as gatekeepers for services. The physicians partner with the State's designated agency to provide care management when patients need long term care. The State provides utilization reports to participating practices. A 
logical next step is to select quality indicators discernible from the claims data and reward practices that achieve desired outcomes. While this approach promotes better management of existing services and can include appropriate financial incentives, it does not promote flexibility or substitution of services, since payments are still triggered by providing services that have been predefined as reimbursable.

Partial capitation refers to payment systems in which some services are prepaid through capitation but some remain fee-for-service. In a rural setting, this can be a way of containing risk for a nascent local organization while still allowing some flexibility of services and providing incentives for efficiency. Depending on how the capitated payment is structured, it can also allow an organization to avoid being treated as an $\mathrm{HMO}$ or other risk-bearing entity subject to large risk reserve requirements. Key policy questions include what to capitate and how to avoid cost-shifting to the fee-for-service side of the equation. In general, program designers should consider leaving in fee-for-service those services they want to promote (e.g., home care) and capitating services that are overutilized. An example of a partial capitation strategy is the one used with the Wisconsin Partnership Program site in Eau Claire. Medicaid services were partially capitated, and Medicare services remained entirely fee-for-service during a multi-year start-up period. Both (Medicare and Medicaid) became fully capitated after the site had gained considerable experience.

Other risk limitation mechanisms include risk corridors and reinsurance. Risk corridors define the ways in which losses and profits are divided between a plan or program and a payer. For example, in the Program for All-inclusive Care for the Elderly (PACE), risk corridors were used in the first three start-up years of the program to provide the time necessary to develop and refine the service system. If a program's revenues exceeded its expenditures, a risk reserve was created that was used to fund losses or create a risk reserve for future years. If the program's expenditures exceeded its revenues, the losses were shared by the program and the payer. The use or purchase of re-insurance for high cost cases is another method of reducing financial risk. Re-insurance can be structured in a number of different ways. In Arizona, the State buys commercial reinsurance that covers the cost of care for individual cases that exceed certain thresholds. For catastophic cases associated with certain pre-defined conditions, such as transplants or hemophilia, the reinsurance covers either a certain percentage of the costs or a pre-established amount for the condition. In other states, the Medicaid agency itself offers reinsurance, or plans may be responsible for purchasing their own re-insurance.

\section{Conclusions}

Full capitation of acute and long term care payments is an urban financial integration model that is often not applicable in rural areas. Many rural areas do not have adequate infrastructure to support full capitation models, nor are such models necessarily consistent with the common rural area goal of preserving and strengthening existing providers.

Rural areas may still want to pursue service integration to achieve greater flexibility and less fragmentation of services. A number of incremental payment approaches are more feasible for these areas than full capitation, yet still support some integration of services. These include the creationof fee-for-service incentives, partial capitation and other risk limitation strategies. 
Financing Options for Integration in Rural Areas

\begin{tabular}{|c|c|c|c|}
\hline & Key Features & Risk Management & Pros+ and Cons- \\
\hline $\begin{array}{l}\text { Traditional } \\
\text { Fee for } \\
\text { Service }\end{array}$ & $\begin{array}{l}\text { Services paid on a } \\
\text { per unit basis. }\end{array}$ & No risk to providers. & $\begin{array}{l}\text { +Existing providers } \\
\text { can participate } \\
\text { directly. } \\
\text {-Little opportunity to } \\
\text { make services more } \\
\text { flexible. }\end{array}$ \\
\hline $\begin{array}{l}\text { Managed } \\
\text { Fee for } \\
\text { Service }\end{array}$ & $\begin{array}{l}\text { Payments remain } \\
\text { FFS, but } \\
\text { management and } \\
\text { coordination of } \\
\text { services are } \\
\text { strengthened. } \\
\text { Claims data is } \\
\text { actively analyzed } \\
\text { and use to change } \\
\text { provider practices } \\
\text { over time. }\end{array}$ & $\begin{array}{l}\text { Little risk to providers. } \\
\text { Incentive payments } \\
\text { may be offered to } \\
\text { reward certain desired } \\
\text { outcomes. }\end{array}$ & $\begin{array}{l}\text { +Existing qualified } \\
\text { providers can } \\
\text { participate directly. } \\
\text { +Allows for targeted } \\
\text { financial incentives. } \\
\\
\text {-Little opportunity to } \\
\text { make services more } \\
\text { flexible. }\end{array}$ \\
\hline $\begin{array}{l}\text { Partial } \\
\text { Capitation }\end{array}$ & $\begin{array}{l}\text { Some but not all } \\
\text { services are } \\
\text { included in the } \\
\text { capitation payment. } \\
\text { Partial capitation } \\
\text { may be from } \\
\text { Medicare and/or } \\
\text { from Medicaid. }\end{array}$ & $\begin{array}{l}\text { Organization needs } \\
\text { capacity to } \\
\text { manage/monitor } \\
\text { services. } \\
\text { Responsibility for risk } \\
\text { management, quality } \\
\text { oversight, payment } \\
\text { can be shared with } \\
\text { other entities through } \\
\text { ASO arrangements or } \\
\text { HMO partners. }\end{array}$ & $\begin{array}{l}\text { Promotes cost } \\
\text { consciousness and } \\
\text { allows flexibility of } \\
\text { benefits. } \\
\text { Cost shifting to fee for } \\
\text { service system is a } \\
\text { problem. } \\
\text { Difficult to administer } \\
\text { and reconcile } \\
\text { payments with payers. }\end{array}$ \\
\hline $\begin{array}{l}\text { Full } \\
\text { Capitation }\end{array}$ & $\begin{array}{l}\text { All inclusive payment } \\
\text { rate paid to a single } \\
\text { entity that is } \\
\text { financially } \\
\text { responsible for risk. }\end{array}$ & $\begin{array}{l}\text { Organization must } \\
\text { have established } \\
\text { network of providers, } \\
\text { be able to pay } \\
\text { providers, meet quality } \\
\text { assurance standards } \\
\text { and have systems } \\
\text { capacity to monitor } \\
\text { service use and } \\
\text { reporting } \\
\text { requirements. } \\
\text { Risk can be shared } \\
\text { through re-insurance, } \\
\text { risk corridors, or risk } \\
\text { pools. }\end{array}$ & $\begin{array}{l}\text { Difficult in rural areas } \\
\text { with low population } \\
\text { base and low } \\
\text { penetration of } \\
\text { established managed } \\
\text { care providers. } \\
\text { May conflict with goals } \\
\text { of local area providers } \\
\text { and rural market } \\
\text { conditions. }\end{array}$ \\
\hline
\end{tabular}




\section{Introduction}

A major concern with fee-for-service reimbursement is that it forces consumers into rigid categories of service, whether or not those services truly meet their needs. This is a particular concern when long term care is needed, because community-based long term care services tend to be under-funded, resulting in overuse of substitutes that are expensive and medical in nature, such as hospital, nursing home and home health care. The hope of integration is that consumers will get the appropriate level of care when they need it. This is premised on a fundamental re-ordering of financial incentives, in which providers are financially motivated and work together to substitute high-touch for high-tech services whenever clinically appropriate.

The urban response to perverse fee-for-service incentives has been to experiment with capitated Medicare and Medicaid payments that integrate acute and long term care funding, creating flexible pools of dollars at the plan or provider system level, to be used to provide what the consumer needs when the consumer needs it, regardless of whether it appears on a list of approved services. In addition to providing flexibility, capitation reverses the incentives: hospital days and long-term nursing home stays become costly services to use sparingly, while sub-acute care, ambulatory care, home care and various forms of residential care become attractive substitutes demanded by the plan, stimulating development of the marketplace with little need for government planning.

Combining Medicaid and Medicare funds also integrates the acute and long term care financing and reduces opportunities for cost shifting. For example, current implementation of prospective reimbursement for Medicare home health is expected to 
result in a cost-shift to Medicaid home health, particularly for higher-cost beneficiaries who need more service than agencies can provide within Medicare reimbursement limits. For dually eligible beneficiaries, agencies may be able to move patients from Medicare to Medicaid funding streams.

Can capitation really work such wonders for rural long term care systems? To date, there is precious little experience with capitated, integrated care, and what does exist is mostly in urban areas. While the intuitive appeal of capitation is undeniable, we should carefully analyze whether it is feasible in rural areas and what its implications are for various stakeholders in rural health care. Rural health program designers must ensure that the payment and financing systems they develop:

- support specific program goals; and

- are compatible with available service delivery vehicles and local market conditions.

\section{Financing and Payment Must Support Specific Program Goals.}

Any financing and payment system for an integrated long term care system must be tailored to meet the specific goals of the program and the people and the area served by the program. A key question is whether rural integration projects share the goals of the urban demonstrations undertaken to date. Common goals have included the following:

- To pay plans and providers fair and reasonable amounts, while promoting efficiency and financial accountability;

- To diminish opportunities for cost shifting between acute and long term care;

- To provide incentives for high quality of care; and 
- To support the right care at the right time generally, and to encourage the use of home- and community-based services specifically. Integration of multiple funding streams (e.g.; Medicaid, Medicare, State-funded home care, Older Americans Act services, etc.) through capitation is attractive because it is at least a theoretically straight forward approach that can support all the goals above, particularly if the goals are specifically considered in determining the specifics of the capitation.

It may be, however, that the goals of a rural integration project are different from or in conflict with the goals listed above, and that capitation is therefore unnecessary or likely to produce unintended results. Program specific goals in rural areas are likely to be modest and incremental. For example, goals of a rural program may include the following:

- To protect local providers, such as hospitals and nursing homes. In many rural communities, the cumulative pressures of Medicare prospective hospital payments (DRGs), phase-out of Medicaid disproportionate share hospital payments (DSH), and recently implemented skilled nursing and home health prospective payments threaten the financial viability of facilities and agencies that comprise the heart of the health care system and are often the largest employers in the community. Depending on how the payment is structured, capitation could result in lower payments to these providers, since managed care organizations typically seek discounts from providers.

- To develop a managed care infrastructure. In some rural areas, a specific goal will be to move toward managed care principles by stimulating the development of 
an integrated service delivery and financing infrastructure. This may include the development of provider networks to coordinate service delivery, the reorganization of medical staffs to monitor service use and quality across a spectrum of services, and the development of administrative systems to gather data, pay providers and assume some financial risk. In instances where entities do not exist or are not strong enough to bear full risk under capitation, other incremental approaches may need to be considered.

- To expand access to services generally. In many rural areas, health services are in short supply generally. Capitation is not likely to solve a general health supply shortage problem. In general, managed care entities depend on the opposite being true: they extract discounts from health providers who have excess capacity and are therefore willing to negotiate discounts in return for volume. Integration through capitation also presumes a downward substitution of services, and is not designed to expand services across-the-board.

\section{Financing and Payment Must be Compatible With Available Service Delivery Vehicles and Local Market Conditions.}

Conceptually it is possible to envision and design integrated service and financing systems that meet the particular goals of a rural community. In practice, the organizational structures and financing systems must be compatible with available service delivery systems, local market conditions and the historical practice patterns in the area. While a lot of attention has focused on the issue and need for integrated financing approaches, an 
important question for rural areas is whether an organization can build the appropriate administrative, management and organizational systems to support integrated financing. If not, the typical urban financing arrangement will not apply to a given rural integration effort, and attention will need to be given to one or more of the alternatives discussed in Section IV, below. Risk-bearing integration vehicles that have emerged to date include commercial plans (including those that have Medicare risk contracts), Medicaid plans (including those formed by counties), and various forms of provider-sponsored plans.

\section{A. Commercial Plans (Including Medicare+Choice Plans)}

In areas with heavy or growing managed care penetration, commercial health plans have emerged as organizations willing to take on risk-based long term care integration. These have included Medicare plans, formerly known as Medicare HMOs or TEFRA HMOs, now known as Medicare+Choice plans under the Balanced Budget Act of 1997 (BBA). Until the requirement was eliminated by the BBA, Medicare plans were required to have at least $50 \%$ commercial enrollment.

The Texas Star+Plus demonstration is a recent example of a program that is integrating financing through commercial plans. (University of Maryland, Center on Aging, 1999) The State contracts with three commercial HMOs and pays them a capitation for most Medicaid services, including long term care. The demonstration is located in Harris County, dominated by Houston, the fourth largest city in the country. The area was chosen by State Medicaid officials in part for its highly competitive market conditions and also because Harris County's Medicare managed care rates are above the national average. About half of the 54,000 beneficiaries targeted for Star+Plus were dually eligible for 
Medicare and Medicaid, and the State wanted at least two of their plans to have Medicare risk contracts with HCFA so that full financial integration of Medicare and Medicaid payments could be achieved at the plan level. Because Medicare law guarantees a choice of fee-for-service to Medicare beneficiaries, however, financial integration is not assured in this "piggy back" model: in the first year of the program, most dually eligible Star+Plus members have retained fee-for-service Medicare.

Clearly, a number of urban factors influenced the financing scheme developed for Star+Plus, making it difficult to export to rural areas:

- The Houston market is huge and commercial plans are competing fiercely for market share;

- Through the mandatory Medicaid enrollment, the State offered plans a large risk pool of 54,000 lives;

- Medicare managed care rates were above the national average in Harris County, offering rewards to plans that could receive capitated Medicare and Medicaid payments.

Like Texas, Maine had originally been drawn to Medicare HMOs as a convenient vehicle for integrating Medicaid and Medicare payments, but only one currently exists in the State, and it did not express interest in the MaineNET demonstration project. The MaineNET counties, like nearly all Maine counties, have Medicare managed care rates that are below the national average. As a result the Maine demonstration was redesigned to reflect the local market conditions. At this time a primary care case management 
(PCCM) model is under development as an incremental approach to integration of services in a rural county in Maine. (Maine Department of Human Services, 1999)

To date, Medicare HMOs have had very little presence in rural areas generally. This was due in large part to the relatively low Medicare capitation rates in rural areas, derived from fee-for-service average expenditures that have been lower historically in rural than in urban areas. The Balanced Budget Act of 1997 reduces the gap between rural and urban rates by gradually blending national and local averages. Rural areas with Medicare expenditures below the national average should see their rates rise, possibly making them more attractive to Medicare+Choice plans in the future. However, it is still too early to tell what the market response will be.

In a Colorado demonstration involving a Medicare HMO, the BBA had a negative impact on Medicare rates and has forestalled the full financial integration originally planned for Mesa County, an area on Colorado's western slope that is largely rural. The proposed contractor, Rocky Mountain HMO, currently receives a Medicaid capitation from the State for primary and acute care and has had a Medicare cost contract with HCFA for several years. Under the Colorado Integrated Care and Financing Project, Rocky Mountain HMO would have converted its Medicare cost contract to a risk contract, making it eligible for capitated Medicare payments from HCFA, and the State would have added to its existing capitation funding for Medicaid and State-only long term care services. However, the BBA resulted in a lower Medicare rate than originally projected for the demonstration, making a Medicare capitation unfeasible. (University of Maryland, Center on Aging, 1999) The State 
is proceeding to add long term care to its capitation, but Medicare services will remain feefor-service.

\section{B. Medicaid Plans (Including Counties)}

As an alternative or supplement to commercial plans, Medicaid plans may offer a vehicle for risk-based integration. Options include adding long term care to existing Medicaid primary and acute care plans, as Minnesota did to create its Senior Health Options program, or creating comprehensive plans through counties or other governmental entities that already have a stake in the long term care system.

Minnesota contracts with three plans in its Senior Health Options (MSHO) demonstration, building on its longstanding Prepaid Medical Assistance Program (PMAP). Under PMAP, plans receive a Medicaid capitation for primary and acute care. The State recognized that, for dually eligible beneficiaries, PMAP addresses only a small portion of care, since long term care services and Medicare services were not included in the capitatation. The State developed a voluntary integrated option for dually eligible elderly beneficiaries that adds long term care to the Medicaid capitation and triggers a capitated Medicare payment from HCFA to the plan. (Booth et. al., 1997)

In Arizona, prior to the creation of the Arizona Long Term Care System (ALTCS) in 1989, counties were responsible for long term care services. Arizona was the only State not offering Medicaid long term care services, having only begun accepting federal matching dollars for primary and acute care in 1982 with the creation of its $\S 1115$ Arizona Health Care Cost Containment System (AHCCCS). When the State proposed adding ALTCS as a fully capitated primary, acute and long term care Medicaid program for low 
income residents with significant long term care needs, many counties, including some in very rural parts of the State, created risk-bearing organizations to accept the capitated payments, which would include federal Medicaid matching funds for the first time. ALTCS authorizing legislation recognized the unique historical role of counties by designating the two urban counties (Maricopa and Pima) as the State's exclusive ALTCS contractors in the Phoenix and Tucson areas, and the remaining thirteen counties were given first right of refusal in their areas. (McCall and Korb, 1994) The lesson from Arizona is that risk is relative. With the promise of additional federal dollars and continuing control of the long term care system, taking a capitation was a feasible and manageable option.

\section{Provider Sponsored Organizations}

Since passage of the BBA, the term Provider Sponsored Organization (PSO) gained new attention as a type of managed care entity newly eligible to participate in the Medicare managed care program. Here, we use the term more generally to refer to a provider-based organization that accepts risk for a comprehensive set of services through capitated payments.

The Program for All-Inclusive Care for the Elderly (PACE) is an early example of a provider-based approach to risk-based integration that may be viable in some rural areas. Currently, at least one site, Palmetto SeniorCare based in Columbia, South Carolina, (population around 100,000) serves a sizable surrounding rural area. Designed to serve exclusively people whose needs qualify them for nursing home level of care, traditional PACE sites offer community-based long term care through staff physicians and interdisciplinary team members who have efficient access to members through their 
attendance at day centers. A site receives capitated Medicaid payments from the state and capitated Medicare payments from HCFA and is financially responsible for all care, contracting with hospitals and nursing homes for those services.

PACE programs require significant start-up capital, estimated at $\$ 1-1.5$ million. (State Work Group on PACE, 1999) Start-up costs include capital renovation of a day center and operating losses for about the first 18-24 months, when centers operate below break-even census. In the early days of the PACE demonstration, many of these costs were supported by The Robert Wood Johnson Foundation, but new sites starting today must raise the capital. Many PACE sites are sponsored by hospitals. It is unclear whether PACE sites could be viable without an urban base. Because PACE has a relatively narrow target group (dually eligible beneficiaries who are Medicaid eligible, nursing home certifiable and at least 55 years of age) and is entirely voluntary, sites have found it a constant challenge to maintain and exceed the break-even enrollment of 250-300. Assuming no greater than $25 \%$ penetration, existing sites advise launching a program only if at least 1,000 potential members live in the service area. (State Work Group on PACE, 1999)

\section{A Range of Financing and Payment Strategies}

The appeal of fully capitated financing models is conceptually attractive. Capitation offers a flexible funding pool and, if multiple payers participate (most importantly, Medicaid and Medicare), perverse incentives to shift costs and use expensive services are diminished. Most experience with capitation, however, is in urban areas, or at least areas 
with an urban base. It may be that, in order to achieve some degree of integration in rural settings (or at least better coordination of services), alternatives to full capitation will be necessary.

Financial integration can be thought of as a continuum ranging from full capitation of all services to coordinated fee-for-service incentives --- with many variations and combinations in between. While a single capitation rate is often viewed as a necessary feature of a fully integrated system, there are, in fact, many other financing and payment options available. Table 1 provides a summary of the financing options that are currently available or under consideration for integrated LTC service delivery systems. In fact, some of the moremodest and incremental approaches may be more suitable and desirable for rural areas. 



\begin{tabular}{|c|c|c|c|c|}
\hline & Key Features & Risk Management & $\begin{array}{l}\text { Pros/Cons for Rural } \\
\text { Areas }\end{array}$ & Examples \\
\hline Fee for Service & $\begin{array}{l}\text { Services paid on a per unit basis. } \\
\text { Flexibility to substitute community } \\
\text { based services for higher cost } \\
\text { acute care services is limited. }\end{array}$ & $\begin{array}{l}\text { No risk to providers. } \\
\text { Services coordination or } \\
\text { management is minimal. }\end{array}$ & Supports current delivery system. & \\
\hline $\begin{array}{l}\text { Managed Fee for } \\
\text { Service/Coordination }\end{array}$ & $\begin{array}{l}\text { Uses FFS system but strengthens } \\
\text { the management and coordination } \\
\text { of services. } \\
\text { PCP or care partner coordinates } \\
\text { and authorizes service use. }\end{array}$ & $\begin{array}{l}\text { Little risk to providers or } \\
\text { payers. } \\
\text { Payers may pay fee for } \\
\text { coordination of services by } \\
\text { PCP. } \\
\text { Requires access to data } \\
\text { to monitor service use. }\end{array}$ & $\begin{array}{l}\text { Provides an incremental } \\
\text { approach to integration of } \\
\text { services. } \\
\text { Viable option in areas with low } \\
\text { managed care penetration. } \\
\text { Programs that coordinate } \\
\text { Medicaid and Medicare using a } \\
\text { PCCM are untested. }\end{array}$ & $\begin{array}{l}\text { PCCM programs expanded to } \\
\text { include LTC coordination. } \\
\text { Mainenet is in the pre- } \\
\text { implementation stage. }\end{array}$ \\
\hline Partial Capitation & $\begin{array}{l}\text { Some but not all services are } \\
\text { included in the capitation payment. } \\
\text { Partial capitation may be from } \\
\text { Medicare and/or from Medicaid. }\end{array}$ & $\begin{array}{l}\text { Organization needs } \\
\text { capacity to } \\
\text { manage/monitor services. } \\
\text { Responsibility for risk } \\
\text { management, quality } \\
\text { oversight, payment can be } \\
\text { shared with other entities } \\
\text { through ASO } \\
\text { arrangements or HMO } \\
\text { partners. }\end{array}$ & $\begin{array}{l}\text { Promotes cost consciousness } \\
\text { and allows flexibility of benefits. } \\
\text { Cost shifting to fee for service } \\
\text { system is a problem. } \\
\text { Difficult to administer and } \\
\text { reconcile payments with payers. }\end{array}$ & $\begin{array}{l}\text { Medicare -- Carle Clinic as } \\
\text { part of the Medicare } \\
\text { Community Nursing Care } \\
\text { Demonstration. Medicare } \\
\text { component of Mass. Senior } \\
\text { Care Organization. } \\
\text { Medicaid --- Minnesota Senior } \\
\text { Health Options program. }\end{array}$ \\
\hline Full Capitation & $\begin{array}{l}\text { All inclusive payment rate paid to a } \\
\text { single entity that is financially } \\
\text { responsible for risk. }\end{array}$ & $\begin{array}{l}\text { Organization must have } \\
\text { established network of } \\
\text { providers, be able to pay } \\
\text { providers, meet quality } \\
\text { assurance standards and } \\
\text { have systems capacity to } \\
\text { monitor service use and } \\
\text { reporting requirements. } \\
\text { Risk can be shared } \\
\text { through re-insurance, risk } \\
\text { corridors, or risk pools. }\end{array}$ & $\begin{array}{l}\text { Difficult in rural areas with low } \\
\text { population base and low } \\
\text { penetration of established } \\
\text { managed care providers. } \\
\text { May conflict with goals of local } \\
\text { area providers and rural market } \\
\text { conditions. }\end{array}$ & $\begin{array}{l}\text { PACE programs. } \\
\text { Arizona Long Term Care } \\
\text { System }\end{array}$ \\
\hline
\end{tabular}


In the area of long term care in particular, the situation is complicated by the different payers and their rules and regulations (e.g. Medicare payments for primary, acute and skilled level care, Medicaid long term care payments, nutrition and other services funded through the Older Americans Act, and private insurance that extends Medicare or provides long term care coverage). In this section, we will explore some of the Medicare and Medicaid financing options that are available and how they may meet the needs of rural areas.

\section{A. Full Capitation}

Full capitation is the type of payment most often cited in discussions of financial integration and certainly in the private commercial market, this is the usual method for integrating payments and services. In a fully capitated plan, payment for all services are computed on a per person basis and an all inclusive rate is paid to a single entity that is financially responsible for the risks (profits and losses) associated with the capitation amount. In order to accept a capitated payment, an organization must have appropriate administrative, management and organizational systems. These include the ability to establish a network of providers and make payments to them, the ability to influence practice across those providers in order to meet quality assurance standards of the payers, systems capacity to monitor service use and meet specified reporting requirements, and perhaps most fundamentally, expertise at managing financial risk. Plans must also meet applicable state and federal licensure and insurance regulations. The previous section included a description of the commercial, Medicare and Medicaid plans that are currently in operation and that include a full capitation payment. 


\section{B. Risk Sharing}

One of the biggest obstacles that new provider networks or organizations face in developing managed care products is how to manage and protect themselves from the financial risks associated with capitated payments. This may be of particular concern in rural areas where the number of people enrolling in plans is low, making it difficult to spread risk. Risk sharing may be of interest not only to the contractors, but to payers, who have little interest in seeing new program contractors fail financially or reap untoward profits. There are a number of ways to share risk in a managed care program. Some of the more common ways are through the use of re-insurance, the establishment of risk corridors and the use of risk pools. In its recent survey of State Medicaid managed care programs, the National Academy for State Health Policy found that $82 \%$ of states with Medicaid risk programs in 1998 (37 of 45 states) shared risk with contractors, up from $59 \%$ in 1994 (19 of 32 states). (Kaye et. al., 1999) Interestingly, the use of risk sharing has increased along with the number of states that have risk programs.

The use or purchase of re-insurance for high cost cases is one method of reducing financial losses in a managed care program. Re-insurance can be structured in a number of different ways. In Arizona, the state buys commercial reinsurance that covers the cost of care for individual cases that exceed certain thresholds. For catastophic cases associated with certain pre-defined conditions, such as transplants or hemophilia, the reinsurance covers either a certain percentage of the costs or a pre-established amount for the condition. In other states, the Medicaid agency itself offers re-insurance, or plans may be responsible for purchasing their own re-insurance. 
Another way to minimize risk is through the use of risk corridors. Risk corridors define the ways in which losses and profits are divided between a plan or program and a payer. For example, in the PACE program, risk corridors were used in the first three startup years of the program to provide the time necessary to develop and refine the service system. If a program's revenues exceeded its expenditures, a risk reserve was created that was used to fund losses or create a risk reserve for future years. If the program's expenditures exceeded its revenues, the losses were shared by the program and the payer. Corridors can also be used to assure skeptical stake holders (consumer groups, legislators, providers) that excessive profits will not be siphoned out of an area. In the Texas Star+Plus program, for example, the State will share in profits that exceed 3\%, and will reclaim all profit over 7\%. (University of Maryland, Center on Aging, 1999)

Finally, some State Medicaid programs have created risk pools by holding back a percentage of payments to contractors, and distributed the pool among plans based on relative occurrence of certain high-cost events. This is in effect a form of group insurance that only applies in programs with multiple contractors.

\section{Partial Capitation}

The development and use of capitation payments that do not include all services in a single rate (but some subset of services) may be an attractive alternative for rural areas. The use of a partial capitation provides the opportunity for an organization to gain experience in managing the risk for a more limited number of services and to design the capitation to be specific to program goals. Partial capitation can take many forms, depending on the goals of the program and capacity of the entity accepting the risk. 
For example, the Carle Clinic, which operates in 42 predominantly rural counties around Champaign-Urbana, Illinois, participated in the national Medicare Community Nursing Organization (CNO) demonstration, in which a package of home health, outpatient therapies, durable and non-durable medical supplies and ambulance services were capitated, leaving hospital and other Medicare services fee-for-service. In this program, the focus was on developing a nurse partner who would work with the physician to deliver and manage home care and home health services. The partial capitation was developed to provide flexibility to the providers in designing service and care plans that met the needs of the patients without being constrained by the fee for service structure of payments and service delivery. (Coburn, 1998)

HCFA has expressed interest in testing broader applications of Medicare partial capitation. Negotiations are currently underway with Massachusetts to develop a partially capitated Medicare payment as part of the State's Senior Care Organization (SCO) demonstration. In his conceptual analysis of Medicare partial capitation, Joseph Newhouse (1998) has argued that it provides the best of both worlds: the capitated portion of the payment promotes cost consciousness and flexibility of benefits, while the fee-forservice component supports appropriate access to needed services. Such a payment system is not, however, easy to implement. Because of the potential for cost shifting from capitated benefits to those that remain fee-for-service, the partial capitation must be carefully designed to support program goals. Furthermore, a partial capitation system is much more cumbersome to administer, since provider billing systems and payer 
reimbursement systems must be able to recognize which services qualify for fee-forservice reimbursement and which are prepaid in a partial capitation.

Medicaid programs have used various forms of partial capitation in the design of managed long term care programs. In the Minnesota Senior Health Options program, for example, the capitation payment for Medicaid long term care services includes only six months of nursing facility liability. Beyond six months, the managed care organization continues to be responsible for the member's care, but receives a supplemental nursing facility payment. (Booth et. al., 1997) The State of Minnesota would have preferred to extend MSHO risk to include unlimited nursing facility services, but was concerned that managed care plans would not be willing to take on unlimited risk until they had gained experience in the MSHO program.

State Medicaid programs have also used partial capitation extensively to carve out services that have historically been provided by a certain established network of providers. Common examples of this include mental health services and transportation.

Partial capitation has also been used to create Prepaid Health Plans (PHPs) while States await federal Medicaid waivers. Defined in Medicaid regulations as encompassing a "non-comprehensive" package of services, PHPs are responsible for some, but not all Medicaid services under a partial capitation.

Several PACE sites have used the PHP strategy to operate as "pre-PACE" sites while awaiting waivers to operate under full Medicaid and Medicare authority. While the PHP option has allowed new sites to gain experience before operating under full capitation, it has not generally been financially advantageous for pre-PACE sites, since 
they have not been able to offset expanded community long term care services against Medicare revenue during the pre-PACE period. (State Work Group on PACE, 1999)

\section{Administration Service Arrangements}

The integrated financing approaches that have been discussed so far involve some kind of capitated or partially capitated payment arrangement and the assumption of some risk. For rural providers that are interested in managed care, the administrative, management and financial responsibilities of developing a managed care product may seem overwhelming. One option that some provider networks have used is to contract with an insurance organization to manage the administrative aspects of the program, such as billing, service utilization reporting and risk management. For organizations that are in a start-up phase and trying to develop the organization and service delivery structures for managing and coordinating care, partnering with an insurance or other administrative organization may be attractive. This gives the program time to develop an organizational infrastructure and medical management plan that can become the basis for a more formal managed care organization.

\section{E. Managed Fee for Service/Coordination of Care}

Many rural areas do not have the population base, access to services or provider base to make even a partial capitation feasible. Furthermore, long-established referral patterns, provider relationships, and patient preferences may not be amenable to the organizational and administrative requirements of managed care organizations. Neverthless, the interest in and need to provide better ways to coordinate acute and long term care services remains a high priority for many rural areas. In these areas, more 
modest approaches may best meet the needs and goals of the community. One approach is to strengthen the management and coordination of services and particularly the services of people with extensive and ongoing needs. Medicaid programs have developed and implemented Primary Care Case Management Programs (PCCM) for a number of years. In a PCCM program, the Medicaid program contracts with Primary Care Providers (PCPs) to coordinate and authorize service use for a panel of beneficiaries. Historically, the PCCM programs have been used primarily for younger adults and families rather than the elderly, but some States are now looking at adapting the model for elders in need of long term care services.

For example, Maine has proposed linking the PCP to its long term care system through the use of a care partner, envisioned as a nurse practioner or similarly qualified person. Providers would continue to be reimbursed on a fee-for-service basis. When Maine issued a Request for Information as part of its MaineNET rural integration demonstration, no commercial plans expressed any serious interest. MaineNET was proposed for three rural counties in central and northern Maine, offering a target group of 15,000 beneficiaries dispersed over 11,528 square miles, over a third of the State's land mass. (Maine Department of Human Services, 1998) The State has among the lowest penetration rates of managed care in the country and, although the managed care market is beginning to heat up in the more populated southern portion of the State, commercial plans are not yet rushing to the northern reaches.

As a result of the RFI, Maine redesigned its model, moving away from capitated HMO payments and opting instead for an enhanced Primary Care Case Management 
model, in which payments will continue to be fee-for-service but will be monitored closely by the State, and nurse practitioners will be deployed to forge better links between highvolume primary care practices and the State's existing long term care benefits management agency. (Maine Department of Human Services, 1999)

Still untested is the potential for closely coordinating Medicare and Medicaid services in a PCCM model. One obstacle to overcome will be for States to obtain access to live Medicare data if they are to monitor both Medicare and Medicaid. Also unclear is how Medicare and Medicaid incentives can be lined up when both remain fee-for-service.

Two other rural New England States, Vermont and New Hampshire, are exploring ways to assist existing long term care providers with integration efforts. Vermont has created regional coalitions of community providers as part of a legislatively mandated effort to shift the balance of its long term care system toward community-based services. Depending on how the coalitions evolve and whether they are willing to bear risk, they are potential future vehicles for financial integration. In Cheshire County, New Hampshire, a group of providers is working with the State to develop an integrated package of long term care services, but its unclear at this stage whether Medicaid services will be capitated and if so, how the providers will establish a single business entity through which they could accept integrated payments and share risk. (New England States Consortium, 1999.)

\section{Conclusion}

Full capitation of multiple funding streams is generally considered the most effective way to support the clinical integration of acute and long term care for the following reasons:

- It creates a pool of flexible financing; 
- It creates incentives to use less institutional care and stimulates the development of community-based alternatives; and

- It eliminates cost shifting among payers and perverse utilization incentives inherent in fee-for-service.

Full risk capitation, however, may be most applicable in urban settings where managed care infrastructure, including experience in risk management, is better developed, where excess capacity in certain sectors lends itself to discount pricing and where large numbers of consumers can be enrolled to spread risk. Many rural areas have none or few of these characteristics, and may have goals, such as protection of the existing service delivery system, that conflict with the use of full capitation.

A number of alternatives to full capitation have emerged and will be refined as experience is gained. Rural areas considering integration projects should consider carefully whether full capitation is feasible or desired and develop a financing and payment system that suits their needs. 


\section{REFERENCES}

Booth, Maureen, Julie Fralich, Paul Saucier, Robert Mollica and Trish Riley. 1997. Integration of Acute and Long Term Care for Dually Eligible Beneficiaries through Managed Care. College Park, MD: University of Maryland Center on Aging.

Coburn, Andrew, Elise Bolda, John Seavey, Julie Fralich and Deborah Curtis. 1998. Rural Models for Integrating and Managing Acute and Long-Term Care Services. Portland, ME: Maine Rural Health Research Center, Edmund S. Muskie School of Public Service, University of Southern Maine.

Kaye, Neva, C. Pernice and H. Pelletier. 1999. Medicaid Managed Care: A Guide for States, Fourth Edition. Portland, ME: National Academy for State Health Policy.

Maine Department of Human Services. 1999. MaineNET Approach. 1/5/99 Concept Paper. Augusta, ME.

Maine Department of Human Services. 1998. MaineNET Request for Information. Issued June 15, 1998. Augusta, ME.

Newhouse, Joseph P. 1998. "Risk Adjustment: Where Are We Now?" Inquiry 35: $122-$ 131, Summer 1998.

McCall, Nelda and Jodi Korb. 1994. Combining Acute and Long-Term Care in a Capitated Medicaid Program: The Arizona Long-Term Care System. San Francisco: Laguna Research Associates.

New England States Consortium. 1999. New England Dual Eligibility Projects at a Glance. New England States Consortium web site: www.neconsortium.org

State Work Group on PACE. 1999. Issue Brief \#1: Site Selection and Application Process for PACE. San Francisco: National PACE Association.

University of Maryland, Center on Aging, 1999. Medicare/Medicaid Integration Program web site: http://www.inform.umd.edu/aging/MMIP/ 
MUSKIE

SCHOOL

Edmund S. M USKIE SCh o o l of Public Service educates leaders, informs public policy, and broadens civic participation. The School links scholarship with practice to improve the lives of people of all ages, in every county in $M$ aine, and in every state in the nation.

Edmund S. Muskie SCHOOL Of Public SeRVICE

96 Falmouth Street

PO Box 9300

Portland, ME 04101-9300
TELEPHONE (207) 780-4430

TTY (207) 780-5646

FAX (207) 780-4417

www. muskie. usm. maine. edu 